\title{
Risky Sexual Behavior and Associated Factors among Cobblestone Chiseling Daily Laborer, Addis Ababa, Ethiopia
}

Chalachew Sisay $^{1 *}$, Habtamu Abera ${ }^{2}$, Getachew Hailu ${ }^{3}$ and Abay Sisay ${ }^{2}$

${ }^{1}$ Addis Ababa Health Bureau, Public Health Research and Emergency Management, Ethiopia

${ }^{2}$ College of Health Sciences, Addis Ababa University, Ethiopia

${ }^{3}$ Department of Public Health, College of Medicine and Health Science, Debre Markos University, Ethiopia

\begin{abstract}
Background: In recent years, cobble stone road creation has become one of the most successful infrastructure and job creation in Ethiopia, with tremendous benefits for the poor rural and urban population segment. Identifying factors associated with cobble stone chiselers laborers risk behaviors is crucial for developing effective prevention strategies. Hence, this study aimed to assess risky sexual behavior and associated factors among cobblestone chiselers, in Hana Mariam, Nifas Silk Lafto Sub City, and Addis Ababa, Ethiopia.
\end{abstract}

Methods: Community based cross sectional study was conducted in March 2015 among cobblestone chiselers. The data entry and analysis was carried out using SPSS version 16 . Association between dependent and independent variables were tested using bivariate logistic analysis, $\mathrm{Cl}$ at $95 \%$. $\mathrm{P}$ value less than 0.05 was considered significant.

Results: The prevalence risky sexual behavior of respondents was $79.4 \%$. Nearly half of the study participants $44.5 \%$ were age group $25-29$ years. About $26.4 \%$ of cobble stone chiselers have had $2-5$ sexual partners in the past 12 months and $42.2 \%$ of study participants did not used condom in the first sexual intercourse. Single by marital status were about nine times more likely had risky sexual practices as compared to divorce $(A O R=8.762,95 \% \mathrm{Cl}=4.672$ 16.433 ) in the study participant whose educational status from grade 5-8 and grade 9-12 were about 3 and 4 times more likely practices risky sexual behavior than those individuals whose educational level were write and read (AOR=3.084, $95 \% \mathrm{Cl}=1.328-7.162)$ and $(\mathrm{AOR}=4.224,95 \% \mathrm{Cl}=1.532-11.629)$. Those who drink alcohol daily were 6.277 times more likely practicing risky behavior as compared to those not drunk (AOR=6.277, 95\% $\mathrm{Cl}=1.622-24.298)$.

Conclusion and recommendation: The prevalence of risky sexual behavior among cobble stone chiselers daily laborers was higher; therefore, critical health education that aimed at bringing behavioral changes should be planned and implemented by giving emphasis on identified risk sexual behavior.

Keywords: Risky sexual behavior; Cobble stone; Chiselers; Addis Ababa; Ethiopia

Abbreviations: AIDS: Acquired Immuno Deficiency Syndrome; AOR: Adjusted Odds Ratio; CI: Confidence Interval; CSW: Commercial Sex Workers; EDHS: Ethiopian Demographic and Health Survey; HIV: Human Immunodeficiency Virus; HAPCO: HIV/AIDS Prevention and Control Office; STDs: Sexually Transmitted Diseases; STIs: Sexually Transmitted Infections; SPSS: Statistical Packages for Social Science; VCT: Voluntary Counseling and Testing; WHO: World Health Organization

\section{Background}

Sexual risky behavior includes unprotected sexual activity, inconsistent use of condoms, sex with multiple partners, sex for material gain and early sexual initiation [1]. Worldwide, risky behaviors related to sexual practice in people have taken much of the attention. Even though the proportion those daily sexual onset and use condoms have increased worldwide a great deal of risky sexual behavior continues. Because of this, peoples experience a large number of unplanned pregnancies and sexually transmitted disease including HIV/AIDS [2].

The largest proportion of STIs occur in developing nations, led by south and Southeast Asia, followed by Sub-Saharan Africa, Latin America and the Caribbean [3]. Ethiopia, like sub-Saharan African countries with high HIV prevalence, with a total estimated numbers of $1,116,216$ people living with HIV in 2009 , of which 658,843 are females [4]. Even though HIV prevalence tends to be higher in urban settings than in rural areas, Ethiopia has the most pronounced difference in HIV prevalence where urban dwellers are eight times more likely to be HIV infected than people living in rural areas [5].
Adolescents and young adults are risk takers more likely to make decisions about the future without adequately considering the consequences people were engaged in risky sexual activities, which could result sexually transmitted diseases including HIV infection [6]. It was suggested that many young people have got information from different sources with regard to HIV/AIDS; however, the problem is to bring about behavioral change [7].

Globally, 45 percent of all new HIV infections worldwide are occurring among young people aged 15 to 24 years, 500,000 young people are infected with STI per day, approximately 80 million women have unwanted pregnancies every year [8]. The numbers of people newly infected with HIV in 2009 were 2.6 million and there were a total of 1.8 million AIDS related deaths. Since the beginning of the epidemics, almost 60 million people have been infected with HIV and 25 million people have died of HIV related causes. In 2009, the global adult prevalence (15-49) was $0.8 \%[5,9]$.

*Corresponding author: Chalachew Sisay, Addis Ababa Public Health Research and Emergency Management, Addis Ababa, Ethiopia, Tel: +251924336220; +251912053816; E-mail: chalesisay19@gmail.com

Received January 05, 2018; Accepted April 12, 2018; Published April 19, 2018

Citation: Sisay C, Abera H, Hailu G, Sisay A (2018) Risky Sexual Behavior and Associated Factors among Cobblestone Chiseling Daily Laborer, Addis Ababa, Ethiopia. J AIDS Clin Res 9: 766. doi: 10.4172/2155-6113.1000766

Copyright: ( 2018 Sisay C, et al. This is an open-access article distributed under the terms of the Creative Commons Attribution License, which permits unrestricted use, distribution, and reproduction in any medium, provided the original author and source are credited. 
In sub-Saharan Africa the main risk factors for high HIV transmission include population movement, poverty and/or unequal distribution of wealth, gender inequality and various cultural influences and adult HIV/AIDS prevalence was 5\% in 2009. These include refugees, mineworkers, truck drivers, traders and migrant farmer are all leave their homes for long periods of time. During mobility, rates of sexual partner exchange increase tremendously. Transient men may have sex with commercial sex workers (CSW) or with multiple high-risk sexual partners and might bring STDs including HIV to their wives or regular sexual partners. The various risk factors that related to sexual behavior in this case which was the most important determinant of the spread of HIV-1 was the proportion of men engaging in sexual relationships with people other than their spouses $[10,11]$.

According to the 2005 Ethiopian demographic and health survey report, the prevalence of HIV in Addis Ababa is 5.2\%, which is next to Gambela region $6.5 \%$, highest in Ethiopia. A higher proportion of Ethiopian who attended secondary school (3.1\%) is HIV positive than those with less education or with more than a secondary school education. Men and women in the highest wealth quintile have the highest HIV prevalence (3.9\%). Among women age 25-49 years, 32\% had sexual intercourse before age 15 years, $65 \%$ before age 18 years and by age 25 years most Ethiopian women have had sexual intercourse [12].

Early sexual debut increases young peoples' risk for infection with HIV and other sexually transmitted infections. Youth who begin early sexual activity are more likely to have high-risk sex or multiple partners and are less likely to use condoms [13]. Therefore, delaying sexual debut is the pillar for the prevention of HIV and other sexually transmitted infections among young people $[14,15]$.

According to the Addis Ababa city roads authority, in recent years, cobblestone road creation has become one of the most successful infrastructure and job creation programs in the country, with tremendous benefits for the urban poor and rural migrants. It has created hundreds of thousands of jobs, greatly improved urban mobility and built collaborative relationships between communities and local authorities. The investments in cobblestone roads have also attracted international attention. In 2013, the authority spent 2,124,968,595.16 birr for cobblestone production mainly in the fourth quarter of the fiscal year. The authority can produce $431,130,460$ cobblestones and $83,992.67$ meter cube white achuma raw stone in the five cobblestone production places including Hana Mariam cobblestone production site $[16,17]$. So that cobblestone chiselers are both male and female urban and rural young population segment. Cobblestone newly emerged working environment not given much attention risky sexual behaviors in the area.

Hence, the purposes of this study is to assess the prevalence risky sexual behavior and associated factors in cobblestone site and examine the nature of the relationship between cobblestone chiselers and risky sexual behaviors in Nifas Silk Lafto Sub-City, Addis Ababa. Therefore, this study will fill the research gap on the area and will be applicable on the policy making and program implementation regarding risky sexual behaviors in micro and small enterprises.

\section{Methods}

A community based cross sectional study design was conducted on randomly selected cobblestone chiseling enterprise in Hana Mariam cobblestone site, which is found in woreda 1, Nifas Silk Lafto Sub City Addis Ababa. It's one of the five cobblestone site in Addis Ababa which found in the, Nifas Silk Lafto sub city, which comprise 57 cobblestone chiseling enterprise. Each enterprise holds different type of membership in size. Total of 4,500 members: 3680 are men and 820 are women cobblestone chiselers. Many participants are previously unemployed youths, who have now obtained new skills and livelihood strategies as part of members' were urban and rural young migrants. The current study was conducted from March 1-25, 2015 in Hana Mariam, Nifas Silk Lafto Sub-City [18].

\section{Sample size determination and sampling procedure}

The source populations were cobble stone chiseling enterprise in Hana Mariam cobble stone site, which comprise 57 cobble stone chiseling enterprise. Each enterprise holds different in size of members. Total of 6,497 members were 4,277 men and 2,220 women cobblestone chiselers distributed in 57 Cobble stone Chiseling Enterprise. Hence from 57 cobblestones chiseling enterprise 30 of them who work chiseling cobblestone greater than 1 year in Hana Mariam cobblestone site were the study populations [19].

This study included, those who working at Hana Mariam cobblestone site chiseling cobblestone for more than one year and working currently in the cobblestone site, while the study exclude subject were enterprises who were paving cobblestone and cracking big stones. Also an individual unable to write and read and individuals not able to respond

Considering these the sample size for this study was determined by using the following assumptions: level of confidence taken to be 95\%, 5\% margin of error and 50\% prevalence of risky sexual behaviors. Assumed $\mathrm{P}$ as $50 \%$ as there was no existing previous data which can serve as base line in this specific study population so as to obtain maximum sample size. So that the actual sample size for the study was computed employing the formula for single population proportion.

$$
\mathrm{n}=\frac{(\mathrm{z \alpha} / 2)^{2} \mathrm{p}(1-\mathrm{p})}{\mathrm{d}^{2}}
$$

\section{n: total sample size}

Z: the standard score (critical value) corresponding to $95 \%$ confidence level $=1.96$

\section{d: marginal error $=5 \%(0.05)$}

p: the estimated proportion of presence of risky sexual behaviors among cobblestone chiseling daily laborers which is not known, so we take $50 \%$ as a proportion for the unknown proportion

Therefore; $\mathrm{n}=(1.96)^{2} 0.5(1-0.5) /(0.05)^{2}$

$$
\mathrm{n}=384=384^{\star} 2=768 ;=>768 \times 10 \%=77=>\text { Total sample size }=845
$$

The study populations were selected by using multistage sampling technique. First, the cobblestone enterprise was selected in the Hanna Mariam site. The total numbers of chiselers in the 30 enterprise are 4500 of which, 3680 were men and then distribute in to 30 different enterprises with different in numbers. All 30 members of enterprises were under list of frame. From this list of frame, the subjects were selected, by using systematic sampling technique to gain the total study sample size, then respectively. Participants were included every 5 intervals (study population (4500)/845(sample size)) in the study unit. The start point was selected with lottery method, i.e., number 3 . Then every $5^{\text {th }}$ interval of the respondents included until the sample size was fulfilled. 


\section{Data collection instruments and procedure}

The data from participants was collected by using structured questionnaire. The questionnaire was originally developed in English and then translated into Amharic and the back to English by another person to check its consistency. The questionnaire include question on socio-demographic characteristic, sexual and reproductive health knowledge contraceptive method, sexual transmitted infection including HIV/AIDS, social norms, gender roles, peer influence, khat and alcohol abuse, sexual behavior and coercion. The data was collected by five trained data collectors were participate in the data collection after being given an intensive one day discussion on data collection tools and collection procedures by the principal investigators.

\section{Data quality control}

To maintain the quality of data a pre-test on $10 \%$ ( 85 cobblestone chiselers) was conducted at different enterprise of actual study area and training for data collectors was given just prior to the study conducted. The principal investigators were closely monitoring the data collection.

\section{Data processing and analysis}

The data was cleaned, edited, coded and entered and analyzed using SPSS version 16 statistical software package. To see the association between dependent and independent variables bivariate logistic analysis was done and to see the interaction effect of confounding variables, multivariate logistic analysis was done. Crude odds ratio with $\mathrm{CI}$ at $95 \%$ for bivariate analysis and adjusted odds ratio with CI at $95 \%$ for multivariate analysis were done. $\mathrm{P}$ value less than 0.05 was considered significant.

\section{Operational definitions}

Risky sexual behavior: A cobblestone chiseler is considered as practicing risky sexual behavior if he/she practice at least one of the following (Multiple sexual partner, Inconsistent use of condom, Casual partner and Sex with commercial sex workers).

Multiple sexual partners: Having two or more sexual partners.

Casual partner: any partner other than marital, commercial or regular partner.

Inconsistent use of condom: Incorrect use or fail to use condom at least once during sexual intercourse until the survey.

Sex with commercial sex workers: Sexual act with commercial sex workers at least ones until the survey.

\section{Results}

\section{Socio demographic of respondents}

A total of 841 cobble stone chiselers were completed selfadministered questionnaire. Four respondents were excluded from the analysis for gross incompleteness and inconsistency of response, making the response rate of 99.5 percent. Majority of the study participants 684 (81.3\%) were male and $362(44.5 \%)$ study participants were in the age group of 25-29 years. Nearly to half $400(47.3 \%)$ of the respondents were married currently. Near to two third of the respondents, 633 (74.9\%) were coming from urban. Regarding the educational level of the respondents about $526(61.5 \%)$ was attended formal education as the detail depicted in Table 1.

\section{Risky sexual behavior}

The prevalence of risky sexual behavior in the cobble stone chiselers

\begin{tabular}{|c|c|c|}
\hline Variable & Frequency & Percent \% \\
\hline \multicolumn{3}{|l|}{ Sex } \\
\hline Male & 684 & 81.3 \\
\hline Female & 157 & 18.6 \\
\hline \multicolumn{3}{|l|}{ Age } \\
\hline $18-24$ years & 268 & 31.7 \\
\hline $25-29$ years & 386 & 44.5 \\
\hline $30-35$ years & 133 & 14.6 \\
\hline $36-39$ years & 54 & 8.8 \\
\hline \multicolumn{3}{|l|}{ Religion } \\
\hline Orthodox & 514 & 60.8 \\
\hline Muslim & 106 & 12.5 \\
\hline Protestant & 207 & 24.5 \\
\hline Catholic & 13 & 1.5 \\
\hline Other & 1 & 0.1 \\
\hline \multicolumn{3}{|l|}{ Marital status } \\
\hline Single & 341 & 40.4 \\
\hline Married & 400 & 47.3 \\
\hline Divorced & 89 & 10.5 \\
\hline Wedded & 11 & 1.3 \\
\hline \multicolumn{3}{|l|}{ Ethnic group } \\
\hline Amhara & 297 & 35.5 \\
\hline Oromo & 124 & 14.7 \\
\hline Tigray & 224 & 26.5 \\
\hline Hadiya & 98 & 11.6 \\
\hline Wolyta & 98 & 11.6 \\
\hline \multicolumn{3}{|l|}{ Residence } \\
\hline Urban & 633 & 74.9 \\
\hline Rural & 208 & 24.6 \\
\hline \multicolumn{3}{|c|}{ Respondent Educational level } \\
\hline Only write and read & 113 & 13.4 \\
\hline From grade $1-4$ & 142 & 16.8 \\
\hline From grade 5-8 & 257 & 30.4 \\
\hline From grade $9-12$ & 269 & 31.1 \\
\hline Above grade 12 & 60 & 7.1 \\
\hline
\end{tabular}

Table 1: Socio-demographic characteristics of respondent among cobble stone chiseling daily laborers in Hana Mariam Cobble stone site, Addis Ababa, Ethiopia $2015(n=845)$.

was $79.4 \%$. From the total respondents $737(87.6 \%)$ reported to have ever had sexual intercourse which includes 532 (78.9\%) were males. Of those who were sexually active, 468 (60.3\%) committed sexual practice before the age 18 years, 115 (77.2) were females. In addition to this about $286(36.9 \%)$ also committed sex between 18-24 years old, of those $254(40.5 \%)$ were male. The main reasons for early sexual debut were regarded love, $252(29.8 \%)$ and desire for sex, 240 (28.9\%), respectively. Of the respondents about 301 (35.6\%) of the respondents had execute sex with boy/girlfriends.

Among the sexual active respondents females 107 (12.7\%) had exposed to unwanted pregnancy and fifty five (6.5\%) were exposed illegal abortion. From the total of sexually active respondent 358 (42.2\%) of them did not use condom at all during first sexual intercourse paired. Regarding the sexual practice with CSW, 266 (31.5\%) of the respondents who had execute sex with CSW and only 225 (26.6\%) of the respondent use condom when execute sex with CSW.

From the study participants those how committed sex after alcohol 
consumption was 261 (31\%) of those 245 (30.1\%) were not used condom while $266(31.5 \%)$ of the respondents chew kchat and $161(19.1 \%)$ of participants execute sex after kchat chewed of them 80 (9.5\%) were used condom, While $170(17.4 \%)$ were not used condom. Out of the total participant $383(45.3 \%)$ had practices sexual intercourse with one sexual partners, while two hundred twenty-three (26.4\%) 2-5 sexual partners in the past 12 months. From the total of respondent who have had sex with commercial sex worker (CSW) only one hundred fiftythree (18.1\%) not used condom while two hundred ninety nine $(35.4 \%)$ were used condom to prevent HIV/AIDs while 211 (24.4\%) were used condom to prevent pregnancy as illustrated in Table 2.

Out of sexual active study participants, 466 (55.1\%) of the respondents had not ever used condom in first sexual intercourse. Regarding sexual partner about 404 (47.8\%) of the respondent have had

\begin{tabular}{|c|c|c|c|}
\hline \multirow[b]{2}{*}{ Variable } & \multicolumn{3}{|c|}{ Frequency } \\
\hline & Male $\mathrm{n}(\%)$ & Female n (\%) & Total n (\%) \\
\hline \multicolumn{4}{|l|}{ Risky behaviors } \\
\hline Yes & $536(78.9)$ & $122(81.3)$ & $658(79.4)$ \\
\hline No & $142(21.1)$ & $45(18.6)$ & $187(22.2)$ \\
\hline \multicolumn{4}{|c|}{ Age at first sexual intercourse } \\
\hline$<18$ years & $352(56.3)$ & $115(77.2)$ & $468(60.3)$ \\
\hline $18-24$ years & $245(40.5)$ & $32(21.5)$ & $286(36.9)$ \\
\hline $25-35$ years & $16(2.6)$ & $2(1.3)$ & $18(2.3)$ \\
\hline Above 35 years & $6(0.95)$ & $0(0)$ & $6(0.77)$ \\
\hline \multicolumn{4}{|c|}{ Ever had sexual intercourse } \\
\hline Yes & $595(87.0)$ & $142(90.4)$ & $737(87.6)$ \\
\hline No & $89(13.0)$ & $15(9.5)$ & $104(12.4)$ \\
\hline \multicolumn{4}{|l|}{ Condom use first sex } \\
\hline Yes & $302(47)$ & $26(17.2)$ & $328(41.3)$ \\
\hline No & $341(49)$ & $125(82.8)$ & $466(58.7)$ \\
\hline \multicolumn{4}{|l|}{ Condom use always } \\
\hline During emergency & $281(42.8)$ & $93(60.7)$ & $374(46.2)$ \\
\hline Sex with prostitute & $266(40.5)$ & 0 & $266(32.9)$ \\
\hline With boy or girl friend & $61(9.2)$ & $41(26.8)$ & $102(12.6)$ \\
\hline Other & $48(7.3)$ & $19(12.4)$ & $67(8.3)$ \\
\hline \multicolumn{4}{|c|}{ Peer pressure during sexual intercourse } \\
\hline Yes & $173(20.5)$ & $57(62.7)$ & $230(28.0)$ \\
\hline No & $494(74.0)$ & $96(62.7)$ & $590(72)$ \\
\hline \multicolumn{4}{|c|}{ With whom execute the first sexual intercourse } \\
\hline With friend & $242(38.1)$ & $59(39.3)$ & $301(38.2)$ \\
\hline Sexual harassment & $126(19.8)$ & $48(32.0)$ & $143(20.2)$ \\
\hline With wife/husband & $143(22.5)$ & $37(24.7)$ & $180(22.0)$ \\
\hline CSW & $130(20.5)$ & 0 & $130(20.5)$ \\
\hline \multicolumn{4}{|c|}{ Number of sexual partner past 12 months } \\
\hline Only one & $214(37.4)$ & $47(24.5)$ & $288(36.1)$ \\
\hline From 2-5 persons & $311(48.2)$ & $93(48.4)$ & $404(50.7)$ \\
\hline Above 5 persons & $93(14.4)$ & $12(6.3)$ & $105(13.2)$ \\
\hline \multicolumn{4}{|c|}{ Sex committed after alcohol consumption } \\
\hline Yes & $225(34.4)$ & $37(28.9)$ & $262(32.8)$ \\
\hline No & $430(65.6)$ & $106(74.1)$ & $536(67.2)$ \\
\hline \multicolumn{4}{|c|}{ Sex committed after khat chew } \\
\hline Yes & $134(24.7)$ & $27(22.3)$ & $161(24.2)$ \\
\hline No & $409(75.3)$ & $94(77.7)$ & $503(75.8)$ \\
\hline \multicolumn{4}{|c|}{ Sex practices with CSW } \\
\hline Yes & $252(39.5)$ & $14(16.3)$ & $266(36.8)$ \\
\hline No & $385(60.4)$ & $72(83.7)$ & $457(90.9)$ \\
\hline
\end{tabular}

Table 2: Percentage distribution sexual behavior among cobble stone chiselers by sex, in Hana Mariam cobble stone site, Addis Ababa, Ethiopia, 2015( $n=845)$.

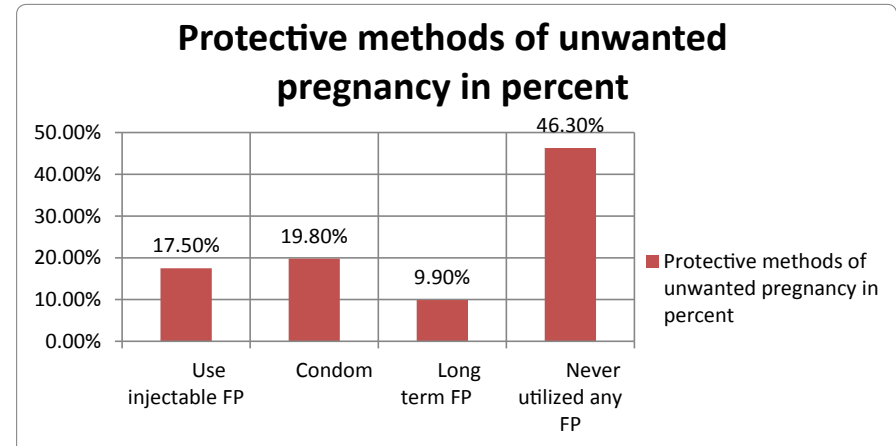

Figure 1: Protective methods of unwanted pregnancy of cobble stone chiselers by percent in Hana Mariam cobble stone site.

two up to five sexual partners. Out of this respondents 150 (12.4\%) of the study participant had manifested with STI. Near to half of the study participant, $319(46.3 \%)$ were never used any family planning methods until the survey conducted as the depicted in Figure 1.

\section{Determents of risky sexual behavior}

Predictors of risky sexual behaviors among cobble stone chiselers in Hana Mariam: After including variables with $p$-Value less than 0.2 bivariate analysis or variable significant ( $p$-value $<0.05$ ), by this assumption, the following were found to be associated on multivariate analysis. This study declared that age 30-35 years old, cobble stone chiselers were about 0.068 times less likely to have had risky sexual practices than those were found age $18-24$ years $(\mathrm{AOR}=0.068,95 \% \mathrm{CI}=0.009$ 0.508 ).

Marital status was statistical significantly associated with risky sexual behavior among the cobble stone chiselers daily labors, single individual were 8.8 times more likely to have had risky sexual behavior than divorced individuals ( $\mathrm{AOR}=8.762,95 \% \mathrm{CI}=4.672-16.433)$. This study indicated that educational status was a significant predictors of risky sexual behavior among cobble stone chiselers, specially individuals whose educational status was from grade 5-8 and from grade 9-12 were about 3 times and 4 times more likely to engaged in risky sexual practices than those individuals whose educational level above grad 12 respectively $(\mathrm{AOR}=3.465,95 \% \mathrm{CI}=1.472-8.157)$ and $(\mathrm{AOR}=4.224,95 \% \mathrm{CI}=1.443-11.318)$. Regarding to cobble stone chiselers age at first sexual intercourse, in the age 30-35 years were about 0.068 times less likely to have had risky sexual behavior than those whose first sexual intercourse engagement was in the age of above 35 years (AOR=0.068, 95\% CI=0.009-0.508). Alcohol consumption also statistically significant with risky sexual behavior, those who were drinking alcohol sometimes 0.203 times less likely practicing risky behavior however drinking alcohol daily 6.277 times more likely practicing risky behavior as compared to those not drank alcohol $(\mathrm{AOR}=0.203,95 \% \mathrm{CI}=0.060-0.809)$ and $(\mathrm{AOR}=6.277,95 \%$ $\mathrm{CI}=1.622-24.298$ ), respectively (Table 3 ).

\section{Discussion}

In recent years, cobblestone road creation has become one of the most successful infrastructure and job creation programmers in the country, with tremendous benefits for the urban poor. It has created hundreds of thousands of jobs, greatly improved urban mobility and built collaborative relationships between communities and local authorities. Because of lack of similar studies on the same study population, we made some comparisons with other potentially risky groups from EBSS, EDHS and other studies whenever appropriate. 


\begin{tabular}{|c|c|c|c|c|c|}
\hline \multirow[t]{2}{*}{ Variables } & \multicolumn{2}{|c|}{ Sexual risky behavior } & \multirow[t]{2}{*}{$\operatorname{COR}(95 \% \mathrm{Cl})$} & \multirow[t]{2}{*}{ AOR $(95 \% \mathrm{Cl})$} & \multirow[t]{2}{*}{ P-value } \\
\hline & Yes & No & & & \\
\hline \multicolumn{6}{|l|}{ Age } \\
\hline $18-24$ years & 213 & 55 & 1 & 1 & \\
\hline $25-29$ years & 335 & 41 & $0.074(0.010-0.551)$ & $0.182(0.075-0.439)$ & \\
\hline $30-35$ years & 117 & 6 & $0.194(0.025-1.475)$ & $0.068(0.009-0.508)$ & $0.009^{* *}$ \\
\hline $36-39$ years & 72 & 2 & $0.199(0.083-0.475)$ & $0.166(0.022-1.276)$ & \\
\hline \multicolumn{6}{|l|}{ Marital status } \\
\hline Single & 329 & 12 & $8.074(4.336-15.034)$ & $8.762(4.672-16.433)$ & $0.000^{\star *}$ \\
\hline Married & 309 & 91 & $0.312(0.040-2.429)$ & $0.312(0.040-2.429)$ & \\
\hline Divorced & 99 & 1 & 1 & 1 & \\
\hline \multicolumn{6}{|l|}{ Educational level } \\
\hline Only read and write & 106 & 7 & $1.789(0.703-4.549)$ & $1.739(0.663-4.563)$ & \\
\hline From grade 1-4 & 127 & 15 & $1.347(0.556-3.267)$ & $1.178(0.478-2.952)$ & \\
\hline From grade 5-8 & 236 & 21 & $3.289(1.440-7.513)$ & $3.465(1.472-8.157)$ & $0.004^{* *}$ \\
\hline From grade $9-12$ & 221 & 48 & $4.188(1.570-11.170)$ & $4.041(1.443-11.318)$ & $0.008^{* *}$ \\
\hline Above grade 12 & 47 & 13 & 1 & 1 & \\
\hline \multicolumn{6}{|l|}{ Age start sex } \\
\hline Age $<18$ years & 438 & 30 & $0.474(0.222-1.014)$ & $0.037(0.005-0.278)$ & \\
\hline Age $=18-24$ years & 277 & 9 & $0.973(0.124-7.620)$ & $0.018(0.002-0.148)$ & \\
\hline Age $=25-35$ years & 17 & 5 & $29.200(5.139-165.900)$ & $0.052(0.003-0.966)$ & $0.047^{\star *}$ \\
\hline Above 35 & 2 & 4 & 1 & 1 & \\
\hline \multicolumn{6}{|l|}{ Condom use } \\
\hline Yes & 284 & 452 & $0.200(0.108-0.371)$ & $9.282(3.966-21.724)$ & \\
\hline No & 64 & 43 & 1 & 1 & \\
\hline \multicolumn{6}{|l|}{ Frequency of condom use } \\
\hline Doesn't use condom use & 340 & 18 & $2.636(1.485-4.677)$ & $7.027(2.700-182.289)$ & \\
\hline Some times & 301 & 42 & $2.862(0.998-8.205)$ & $5.180(1.126-23.834)$ & \\
\hline Most of the time & 121 & 19 & 1 & 1 & \\
\hline \multicolumn{6}{|l|}{ Alcohol consumption } \\
\hline Not drinking at all & 267 & 57 & 1 & 1 & \\
\hline Some times & 303 & 28 & $1.484(0.779-2.825)$ & $0.230(0.060-0.809)$ & $0.033^{\star *}$ \\
\hline One a week & 73 & 5 & $0.962(0.480-1.896)$ & $1.943(0.888-4.256)$ & \\
\hline Daily & 99 & 9 & $1.087(0.394-3.001)$ & $6.277(1.622-24.298)$ & $0.008^{* *}$ \\
\hline
\end{tabular}

** Significant $\mathrm{p}$-value $<0.05$ at AOR

Table 3: Predictors of risky sexual behaviors among cobble stone chiselers daily labors in Hana Mariam cobble stone site, Addis Ababa, Ethiopia, 2015.

The prevalence risky sexual behavior in this study is higher $(79.4 \%)$ than study done in Bahir Dar City and Kombelcha which is $44.6 \%$ and $35.5 \%$, respectively among daily laborers. Thus the possible reason for the higher in this study with that of Bahir Dar City could be due to sample size variation and most of cobble stone chiselers earned monthly as per number of cobble stone chiseled. In addition to this the continuity of work in long time in the site, i.e., not short paired and all of the participants who chiseled cobble more than one year and cloth intimacy with females and males in the working area. The other possible reasons higher result were involvement both male and females and easily accessed Bares and Hotel near to the cobble stone site [20,21].

Regarding sexual practice (87.6\%) of the cobble stone chiseling daily laborers in this study reported to have ever practice sex prior to the survey and from those $56.3 \%$ of male have had their first sex commencement before the age of 18 years. This rate of sexual activity was almost similar to study done in Kombolcha, on assessment of risky sexual behavior for HIV/ AIDS among male daily laborers which is (54.8\%) for male [22], however in the current study the sexual practices before age 18 years were $60.3 \%$ in both sex which is less than study done in Bahir dar city big Construction enterprise daily labors age $15-19$ years were $65.9 \%$ in both sex [21].

In current study $48.2 \%$ male respondent have had two-five sexual partner which was lower as compared to research done on the practices of multi-sexual contacts the major factors for transmission of HIV-STI according to UNAIDS (1999) report, men in Cameroon an average reported 10 life time sexual partners and 5 in Kenya [23]. The possible reason is, majority of cobble stone chiselers was married and living in the urban area.

The main reason not use condom was attributed to: disliking condom $6.9 \%$, unavailability condom during that time $14.6 \%$ partner objection $9.2 \%$, truest of boy or girl friend $0.4 \%$. Which is relatively different from research done in Bahir-Dar $86.6 \%$ having interest in one person, followed by disliking condom $6.4 \%$, sexual partner objection $1.8 \%$ and unavailability of condom $0.6 \%$ [24]. 
The practices of condom used during sex with commercial sex worker of cobble stone chiselers in the past 12 months were $26.6 \%$ which is higher as compared to the research done in 2002 Ethiopian behavioral surveillance survey also demonstrated high rate of inconsistent condom use among the high risk population group across the country $20.6 \%$ of Ground forces group and $16.0 \%$ of the truck driver in the last one year [25]. The possible reason for the higher in this finding were easily access condom in the shop and health institution and most of cobble stone chiselers visiting the health institution also educational status batter than those truck drivers and ground forces.

In the present research cobble stone chiselers have had practices sex after alcohol consumption, of those only $31.0 \%$ were used condom, while $63.4 \%$ were not practices sex after alcohol consumption. However, from those drank alcohol and practices sex only $14.0 \%$ of cobble stone chiselers were used condom and $30.1 \%$ of the not used condom in the last 12 months of sexual practices, this indicate that cobble stone chiselers practices of condom use were lower as compared to research done on among Massachusetts Adolescences indicated that sixteen percent of adolescence who said they had sex after drinking reported using condom less often after drinking than when not drinking [26]. In the current research cobble stone chiseling daily laborer the chance of unwanted pregnancy was $12.7 \%$ which is smaller than previous research done in Ethiopia on unwanted pregnancy was found to be $15 \%$ and $30 \%$ in Gondar and Harrier, respectively. Thus the possible justifications were easily access modern contraceptives in the health institutions and pharmacy and open discussion with relatives on the matter of sexual behaviors $[27,28]$.

This study conclude that age first sexual intercourse is a significant predictors of risky sexual behavior, respondents whose first sex in the age range 30-35 years were about 0.052 times less likely have had sexual risk behavior than individuals who had their first sex was from above 35 years ( $\mathrm{AOR}=0.052$, 95\% $\mathrm{CI}=0.003$ 0.966). Behavioral science researchers agree that abstinence from sex before marriage and delay of sexual debut are among the important strategies that help to reduce the spread of HIV/AIDS and other health impacts, especially among youths [21,29]. A statistical significance association was observed between alcohol consumption and sex, of those who using alcohol daily seven times more likely practicing unprotected sex than not drank alcohol $(\mathrm{AOR}=6.277$, 95\% CI=1.622-24.298). This research agreed with research done in Ethiopia BSS 2002, alcohol consumption in daily threefold increased odds compared to those not using it $[22,30]$.

\section{Conclusion}

Considerable proportions of cobble stone chiseling daily laborers were exposed to high risk sexual behaviors in the study paired, some of the risky sexual behaviors identified were: start first sex age less than 18 years, practicing sex with commercial sex worker, multiple sexual partners and unwanted pregnancy. The rate of self-reported sexually transmitted diseases is also very high among currently sexually active respondents. This finding indirectly showed the extent of unprotected sex that favors exposure to HIV/AIDS, unwanted pregnancy and abortion. Educational status, age, drinking alcohols, and marital status and age at first sex were found as statically associated with risky sexual behaviors among cobble stone chiseling daily laborers.

\section{Recommendations}

Based on the research findings, the following recommendations were forwarded:
1. Critical behavioral change communication activities should be done by sub-city health office, sub-city HAPCO and other organizations working on HIV/AIDS in a sustainable and organized manner to educate cobble stone daily laborers on the identified high risky sexual behaviors.

2. Enhance condom promotion activities using different approaches like youth clubs, community volunteers, condom machines, peer groups and work place distribution.

3. Assure full time availability of condom in bars and hotels frequently visited by these cobble stone chiseling daily laborers.

4. Consider work place intervention like mobile VCT and STIs case management in the cobble stone site.

5. National level or large scale surveys, like the Ethiopian behavioral surveillance survey and other related surveys should consider this segment of population in their future study.

\section{Ethical Considerations}

Ethical clearance was obtained from the ethical clearance committee of Debre Markos University Medicine and Health sciences college ethical clearance committee. Support letter was written to, Nifas Silk Lafto Sub City health office and, Nifas Silk Lafto Sub City cobblestone project office to obtain their support during the data collection process. The necessary explanation about the purpose of the study and about its procedures was done. Consent was also obtained from each respondent; those who were unwilling to participate in the study were respected left. To insure confidentiality, anonymous interview was conducted. Names and others identifying information not used in the study. Health education about substance abuse and HIV/AIDS was given for the respondents after completing the questionnaire.

\section{Availability of Data and Material}

The data sets during and/or analyzed during the current study available from the corresponding author on reasonable request.

\section{Author Contributions}

Chalachew Sisay, Habtamu Abera conceived and designed the study and collected data, performed analysis, interpretation of data and also critically reviewed of this manuscript. Getachew Hailu and Abay Sisay support data collection perform analysis, interpretation of data and also critically reviewed of this manuscript.

\section{Acknowledgement}

We are grateful to Debremarkos University for granting the ethical clearance for conducting the study. Our thanks also extend to those all who cooperated with us in doing this work.

\section{References}

1. http://www.accessmylibrary.com/.pdf

2. National Academy Press (1996) The hidden epidemic: Confronting sexually transmitted disease. Institute of Medicine, Washington, DC.

3. WHO (2001) Global Prevalence and Incidence of Curable STIs. World Health Organization, Geneva.

4. WHO/UNAIDS (2014) Sexually transmitted diseases: Policies and principles for prevention and care. WHO, UNAIDS.

5. $\mathrm{MOH}$, Disease Prevention and Control Department (2004) AIDS in Ethiopia Technical Document for the FFTH Report. MOH.

6. James S (1999) A cultural approach to HIVIAIDS prevention and care UNESCO/UNAIDS, pp: 10-12. 
7. Petere P, Michael B (2002) The epidemiology of HIV and AIDS. AIDS in Africa, pp: 123-124.

8. Coley R, Medeiros B, and Schindler H (2008) Effects of parenting on adolescent sexual risk behaviors. J Adolesc Health 43: 133-140.

9. World Bank Global HIVIAIDS Program (2011) HIVIAIDS in Ethiopia. An Epidemiological Synthesis.

10. Jonathan C, Mark L, Brian W (2005) HIVIAIDS, population mobility and migration in Southern Africa. Defining a Research and Policy Agenda, pp: $1-66$

11. Stephenson GM, Davis JH (1981) Attitudes and voting behavior: An application of the theory of reasoned action. J Progr Appl Soc Psychol 1: 253.

12. https://dhsprogram.com/pubs/pdf/fr255/fr255.pdf

13. FHI, USAID, Youth Net Assessment Team (2004) Assessment of youth reproductive health programs in Ethiopia. FHI, Addis Ababa, Ethiopia.

14. Ateka GK (2001) Factors in HIVIAIDS Transmission in sub-Saharan Africa. J World Health Organ 79: 168.

15. Alem A, Kebede D, Kullgren G (1999) The epidemiology of problem drinking in Butajira, Ethiopia. Acta Psychiatr Scand 397: 77-83.

16. Kebede D, Alem A (1999) The epidemiology of alcohol dependence and problem drinking in Addis Ababa, Ethiopia. Acta Psychiatrica Scand 100: 30 34

17. Ethiopian Herald Newspaper (2014) The social and economic impact of cobble stone in Ethiopia.

18. http://www.2merkato.com/tenders/view/98533

19. https://www.africaphonebooks.com/ethiopia/en-US/addis-ababa-cityadministration-nifas-silk-la

20. Endris B (2007) Assessment of risky sexual behaviour for HIVIAIDS among male daily laborers in Kombolcha town, South Wollo zone, Amhara national regional state, north east Ethiopia. Department of Community Health, Faculty of Medicine, Addis Ababa University.

21. Kassa M, Tesfaye E, Alamrew Z (2013) Risky sexual behaviour among big construction enterprise workers; Bahir Dar city, Amhara regional state, northwest Ethiopia. Int J Clin Med 4: 296-303.

22. Htun NSN, Phoolcharoen W (2009) HIVIAIDS risk behaviors among Myanmar migrants in Bangkok, Thailand. J Health Res 23: 87-88.

23. Boyer CB, Kegeles SM (1991) AIDS risk and prevention among adolescents Soc Sci Med 33: 11-23.

24. Kidane A (2004) Sexuality, perception of risk of HIV/STIs and condom use among high school adolescents in south-Gondar administrative zone, Amhara Region. MPH thesis.

25. Mitike G, Lemma W, Berhane F (2002) HIV/ AIDS behavioral surveillance survey (BSS). Round one, Ethiopia.

26. Ralph W, Lee S (1990) Beliefs about AIDS, use of alcohol and drugs and unprotected sex among Massachusetts adolescents. Am J Public Health 80: 295-299.

27. Ismail S, Bitsuamlak H, Alemu K (1997) High risk sexual behaviors for STD/ HIV, pregnancies and contraception among high school students in rural town of North west Ethiopia. Ethiop J Health Dev 11: 29-36.

28. Kora A, Haile M (1999) Sexual behavior and level of awareness on reproductive health among youths: Evidence from Harar, Eastern Ethiopia. Ethiop J Health Dev 13: 107-113.

29. Ferrario CM, Moore MA, Bestermann W, Colby C, Exuzides A, et al. (2010) COSEHC global vascular risk management quality improvement program Rationale and design. Vasc Health Risk Manag 6: 1135-1145.

30. Kebede D, Alem A, Mitike G, Enquselassie F, Berhane F, et al. (2005) Khat and alcohol use and risky sex behaviour among in-school and out-of-school youth in Ethiopia. BMC Public Health 5: 109. 